Gut and Liver, Vol. 10, No. 5, September 2016, pp. 749-756

\title{
PMK-S005 Alleviates Age-Related Gastric Acid Secretion, Inflammation, and Oxidative Status in the Rat Stomach
}

Yoon Jeong Choi ${ }^{1}$, Nayoung Kim ${ }^{1,2}$, Ju Yup Lee ${ }^{1}$, Ryoung Hee Nam ${ }^{1}$, Ji Hyung Suh ${ }^{1}$, Sun Min Lee ${ }^{1}$, Min Hee Ham ${ }^{1}$, Hyun Jin $\mathrm{Jo}^{1}$, Young Kwang Shim ${ }^{1}$, Yo Han Park ${ }^{1}$, Jong-Chan Lee ${ }^{1}$, Yoon Jin Choi ${ }^{1}$, Hye Seung Lee ${ }^{3}$, and Dong Ho Lee ${ }^{1,2}$

${ }^{1}$ Department of Internal Medicine, Seoul National University Bundang Hospital, Seongnam, ${ }^{2}$ Department of Internal Medicine and Liver Research Institute, Seoul National University College of Medicine, Seoul, and ${ }^{3}$ Department of Pathology, Seoul National University Bundang Hospital, Seongnam, Korea

Background/Aims: The aim of this study was to evaluate the effect of the synthetic S-allyl-L-cysteine (SAC) PMK-S005 on gastric acid secretion, inflammation, and antioxidant enzymes in aging rats. Methods: The rats were divided into four groups at 31 weeks of age and were continuously fed a diet containing a vehicle control, PMK-SO05 (5 or $10 \mathrm{mg} / \mathrm{kg}$ ), or lansoprazole (5 mg/kg). Gastric acid secretion and connective tissue thickness of the lamina propria were evaluated at 74 weeks and 2 years of age. Tumor necrosis factor (TNF)- $\alpha$, interleukin (IL)-1 $\beta$, and COX-2 levels were measured by using enzyme-linked immunosorbent assays (ELISAs) or Western blot assays. Levels of antioxidant enzymes, including heme oxyganase 1 (HO-1) and $\mathrm{NAD}(\mathrm{P}) \mathrm{H}$ :quinone oxidoreductase 1 (NQO-1), were also measured. Results: As the rats aged, gastric acid secretion significantly decreased, and the connective tissue of the lamina propria increased. However, 74-week-old rats in the PMK-S005 group exhibited greater levels of gastric acid secretion than those of the control and lansoprazole groups. The increase of TNF- $\alpha$, IL-1 $\beta$, and COX2 expression in 74-week and 2-year-old control rats were inhibited by PMK-S005. In addition, the decrease in HO-1 and NQO-1 protein expression that occurred with aging was inhibited by PMK-S005 in the 74-week-old rats. Conclusions: These results suggest that PMK-S005 has therapeutic potential as an antiaging agent to ameliorate age-related gastric acid secretion, inflammation, and oxidative stress in the stomach. (Gut Liver 2016;10:749-756)

Key Words: s-allyl-L-cysteine; Aging; Gastric acid; Anti-inflammation; Antioxidants

\section{INTRODUCTION}

The most common gastric disorders in the elderly individuals are gastritis and peptic ulcer disease which are significantly associated with Helicobacter pylori infection and use of nonsteroidal anti-inflammatory drugs (NSAIDs)..$^{1-3}$ Several experimental and clinical studies have shown that aged gastric mucosa has impaired mucosal defense such as decreased mucus and bicarbonate secretion, decreased prostaglandin generation, reduced nitric oxide synthase activity, and impaired sensory nerve response to luminal acid. ${ }^{4-7}$ Therefore, aged gastric mucosa has increased susceptibility to injury by a variety of damaging agents such NSAIDs, ethanol, and hypertonic solution. ${ }^{6-8}$ Especially, NSAID-induced gastric damage and its complications such as acute gastric erosion, ulceration, bleeding, and perforation are encountered very frequently in the old populations., ${ }^{90}$

In addition, reactive oxygen species (ROS) have been known to a major risk factor in tissue damage and aging. ${ }^{11}$ As digestive diseases, including peptic ulcer, are associated with mucosal lipid peroxidation and oxidative damage, the upregulated activity of antioxidant enzymes may play an critical role against oxidative stress in gastrointestinal mucosa. ${ }^{12-14}$ Our group suggested that the lower part of rat gastric mucosa is replaced by connective tissue with accumulation of oxidative products as the rats get old. ${ }^{15}$ In addition, impairment of apoptosis, angiogenesis, and sensory neuron activity via the activation of early growth response protein 1 (Egr-1), phosphatase, and tensin homolog (PTEN) might increase the susceptibility of gastric mucosal injury during aging. ${ }^{15}$

Phytochemicals such as polyphenols are common antioxidants found in food. It has been suggested that phytochemicals

Correspondence to: Nayoung Kim

Department of Internal Medicine, Seoul National University Bundang Hospital, 82 Gumi-ro 173beon-gil, Bundang-gu, Seongnam 13620, Korea

Tel: +82-31-787-7008, Fax: +82-31-787-4051, E-mail: nayoungkim49@empas.com

Received on November 13, 2015. Accepted on December 5, 2015. Published online May 16, 2016

pISSN 1976-2283 eISSN 2005-1212 http://dx.doi.org/10.5009/gnl15584

@) This is an Open Access article distributed under the terms of the Creative Commons Attribution Non-Commercial License (http://creativecommons.org/licenses/by-nc/4.0) which permits unrestricted non-commercial use, distribution, and reproduction in any medium, provided the original work is properly cited. 
possess many beneficial features, such as antioxidant, antiinflammatory, and anticancer properties. ${ }^{16-18} S$-allyl-L-cysteine (SAC), the most abundant organic garlic compounds has long been used as a common dietary supplement and traditional medicine. PMK-S005 is a synthetic SAC, which is a sulfur-containing water soluble amino acid and SAC has been known to possess powerful antioxidant and anti-inflammatory activities in several studies. ${ }^{16,17}$ Aged garlic extract has been reported to increase lifespan and learning in mice, ${ }^{19}$ but the antiaging effect of SAC in the gastrointestinal tract has not been investigated.

Recently, we reported that the gastroprotective effects of PMK-S005 against ethanol- and NSAIDs-induced acute gastric damage rat model. ${ }^{20,21}$ The aim of this study was to evaluate the effect of PMK-S005 on gastric acid secretion and morphological changes with age. In addition, the molecular mechanism underlying its antiaging effect in terms of proinflammatory cytokines, inflammatory mediator as well as antioxidant enzyme was examined.

\section{MATERIALS AND METHODS}

\section{Animals}

Male Fischer 344 rats, $H$. pylori free and virus free, were purchased from Orient Co., Ltd., Seoul, Korea, and were raised at our institute. The 31-week-old rats were divided into four groups: control, PMK5, PMK10, and lansoprazole group ( $\mathrm{n}=10$ in each group) and housed in a cage maintained at $23^{\circ} \mathrm{C}$, with 12:12-hour light-dark cycles under specific pathogen-free conditions. The control group was fed with ad libitum only Purina rat chow and PMK5, PMK10, and lansoprazole group were fed with rat chow containing $5 \mathrm{mg} / \mathrm{kg}$ of PMK-S005, $10 \mathrm{mg} / \mathrm{kg}$ of PMK-S005, and $5 \mathrm{mg} / \mathrm{kg}$ of lansoprazole per day until sacrifice, respectively. All experimental procedures described here were approved by the Institutional Animal Care and Use Committee of Seoul National University Bundang Hospital (IACUC number: BA1304-127/033-02).

\section{Measurement of gastric acid secretion}

The level of acid secretion was measured in each basal and stimulated rat. In the control group, basal and stimulated acid secretion level were measured at 6-, 31-, 74-week, and-yearold rats. In PMK5, PMK10, and lansoprazole groups, those were measured at 74-week and 2-year-old rats. The rats were starved but allowed water for 24 hours prior to the experiments. After measurement of body weight, the rats were anesthetized by zoletil and rompun mixture. The abdomen was gently opened and the esophagogastric junction and pyloric ring were ligated. An overhead lamp was used to maintain core body temperature at $36^{\circ} \mathrm{C}$ to $38^{\circ} \mathrm{C}$. Then the animals were subcutaneously injected with either phosphate-buffered solution for basal acid secretion or histamine (40 mg/kg) with carbachol (10 $\mu \mathrm{g} / \mathrm{kg})$ for stimulated acid secretion. After incubation for 2 hours, stomach was extracted, and gastric juice was collected using $50 \mathrm{~mL}$ conical tube. The acid output $\left(\mathrm{mmol} \mathrm{H}^{+}\right)$was determined by titration with $0.1 \mathrm{~N} \mathrm{NaOH}$ to $\mathrm{pH}$ 7.0. The gastric acid outputs were adjusted by body weight in order to eliminate any effect of the difference of body weight. The results were expressed as mmol $\mathrm{H}^{+} / 2 \mathrm{~h} / \mathrm{mg}$ body weight.

\section{Mucosal histology}

The obtained gastric specimens were fixed in 10\% buffered formalin for histology. The specimens were embedded in paraffin and routinely processed and stained with hematoxylin and eosin (H\&E). The area of the connective tissue was quantified in the lower one-third of the mucosa and the total area of each specimen by using Image-Pro Plus 7.0 (MediaCybernetics Inc., Rockville, MD, USA). ${ }^{15}$ Six specimens were analyzed in each individual. The connective tissue area was expressed as a \% of the total area.

\section{Measurement of tumor necrosis factor $\alpha$, and interleukin $1 \beta$}

An enzyme-linked immunosorbent assay (ELISA) was performed to measure the level of the cytokine expression using the appropriate kits from Hycult Biotechnology (Uden, The Netherlands) and R\&D systems (Minneapolis, MN, USA) by following the manufacturer's instructions. All assays were performed in triplicate, and data are shown as mean \pm standard errors (SEM).

\section{Western blotting for COX-2, heme oxyganase 1, and NAD(P)H:quinone oxidoreductase 1}

Equal amounts of protein from gastric mucosal lysates were subjected to SDS-PAGE analysis, and immunoblotting using the appropriate antibodies was performed as we previously described. ${ }^{15}$ The incubation condition for each antibody is as follows: anti-COX-2 antibody (1:1,000; Cayman Chemical, Ann Arbor, MI, USA), anti-heme oxyganase 1 (HO-1) antibody (1:1,000; Abcam Inc., Cambridge, UK), and anti-NAD(P) H:quinone oxidoreductase 1 (NQ0-1) antibody (1:1,000; Abcam, Inc.).

\section{Statistical analysis}

All statistical calculations were performed using SPSS software version 18.0 (SPSS Inc., Chicago, IL, USA). The results were compared using the Mann-Whitney U test and the Wilcoxon rank sum test. All values are reported as means \pm SEM. Statistical significance was set at $\mathrm{p}$-value $<0.05$.

\section{RESULTS}

\section{Effect of PMK-S005 on age-related change of gastric acid secretion}

Since the mean body weight of F344 rats are significantly increased according to age, we corrected the result of acid concentration by body weight. Weight-adjusted acid output 
levels in both basal and stimulated groups were decreased with age (Fig. 1A). Under basal condition, gastric acid concentration of 74-week and 2-year-old rats was significantly reduced as compared with 6 -week-old rats ( 74 weeks, $p=0.029 ; 2$ years, $\mathrm{p}=0.012$ ). Similarly under stimulated condition, gastric acid concentration of 74-week and 2-year-old rats was significantly lower than that of 6 -week-old rats (74 weeks, $\mathrm{p}=0.01 ; 2$ years, $\mathrm{p}=0.01$ ) (Fig. 1A). In 74-week and 2-year-old rats, no significant differences were found among all experimental groups regarding the basal gastric acid concentration. However, in 74-weekold rats, stimulated gastric acid secretion in PMK5 group was significantly higher than that of control group $(\mathrm{p}=0.029)$ whereas this effect did not persist in 2-year-old rats. The stimulated gastric acid secretion in lansoprazole group was significantly lower compared with control group (74 weeks, $p=0.009$; 2 years, $\mathrm{p}=0.013$ ), which could be explained by pharmacological action (Fig. 1A). The volume of stimulated gastric acid secretion was decreased with age (Fig. 1B). In 74-week-old rats, the volume of stimulated gastric acid secretion of PMK5 group was little bit

A

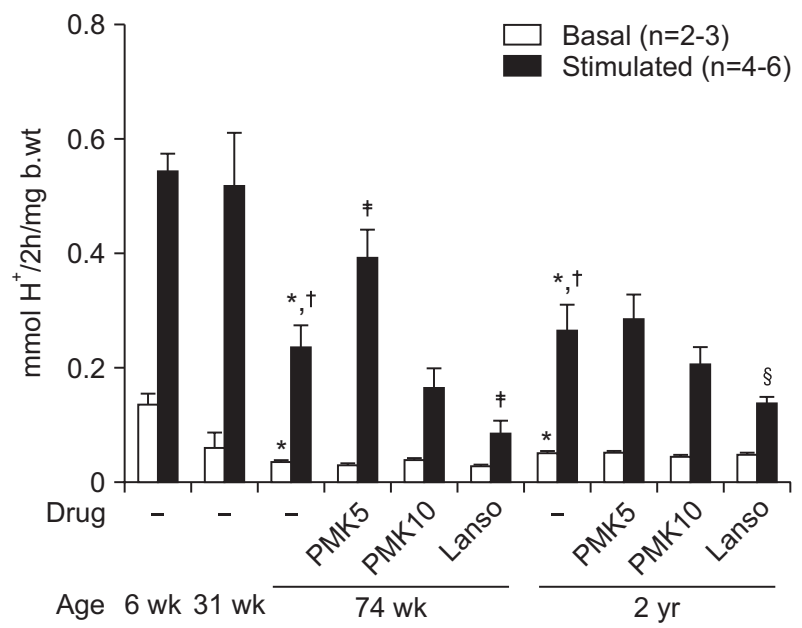

C

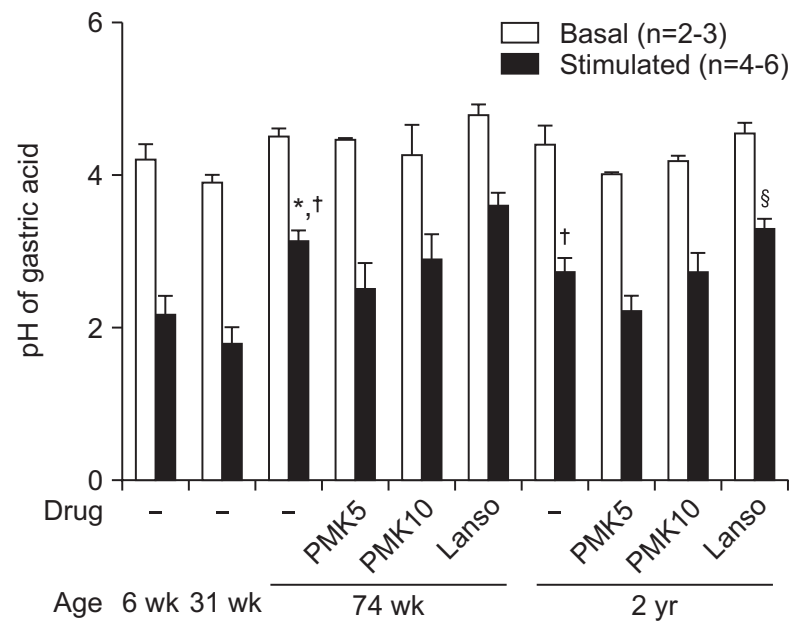

higher than control group but there was no statistical significance. The $\mathrm{pH}$ of stimulated gastric acid secretion was increased with age (Fig. 1C). In 74-week and 2-year-old rats, $\mathrm{pH}$ of gastric acid in PMK5 group was lower compared to control group but there was no statistical significance. Although there was no dose dependent effect of PMK-S005, these results indicate that continuous administration of $5 \mathrm{mg} / \mathrm{kg}$ of PMK-S005 may influence to age-related change of gastric acid secretion.

\section{Effect of PMK-S005 on age-related change of connective tissue area}

Previously, we found that the thickness of connective tissue of lamina propria in the gastric mucosa was increased with age. ${ }^{15}$ Therefore, we examined whether the continuous administration of PMK-S005 could affect this age-related morphological change. As shown in Fig. 2, age-related thickening of connective tissue was also confirmed in this experiment. In 74-week and 2-year-old rats, the connective tissue thickness of lamina propria in both PMK5 and PMK10 groups were lower compared

B

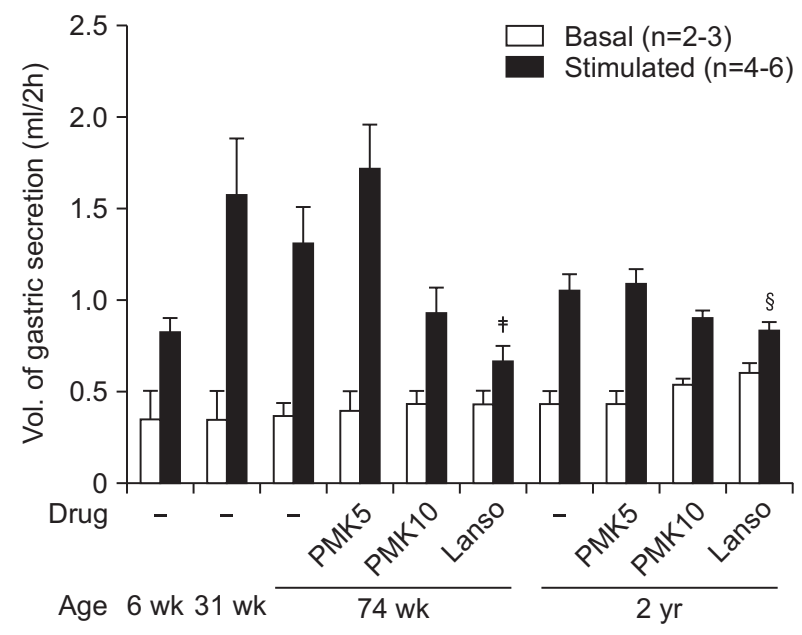

Fig. 1. The effect of PMK-S005 on gastric acid secretion in aging rats. (A) Basal and stimulated acid concentration corrected by body weight. (B) The volume of gastric acid secretion. (C) The $\mathrm{pH}$ of gastric acid. The results are expressed as the means \pm SEM.

PMK5, $5 \mathrm{mg} / \mathrm{kg}$ of PMK-S005; PMK10, $10 \mathrm{mg} / \mathrm{kg}$ of PMK-S005; Lanso, $5 \mathrm{mg} / \mathrm{kg}$ of Lansoprazole. " $\mathrm{p}<0.05$ compared with the 6 -week-old controls; ${ }^{\dagger} \mathrm{p}<0.05$ compared with the 31 -week-old controls; ${ }^{\ddagger} \mathrm{p}<0.05$ compared with the 74 -week-old controls; ${ }^{8} \mathrm{p}<0.05$ compared with the 2-year-old controls. 
A
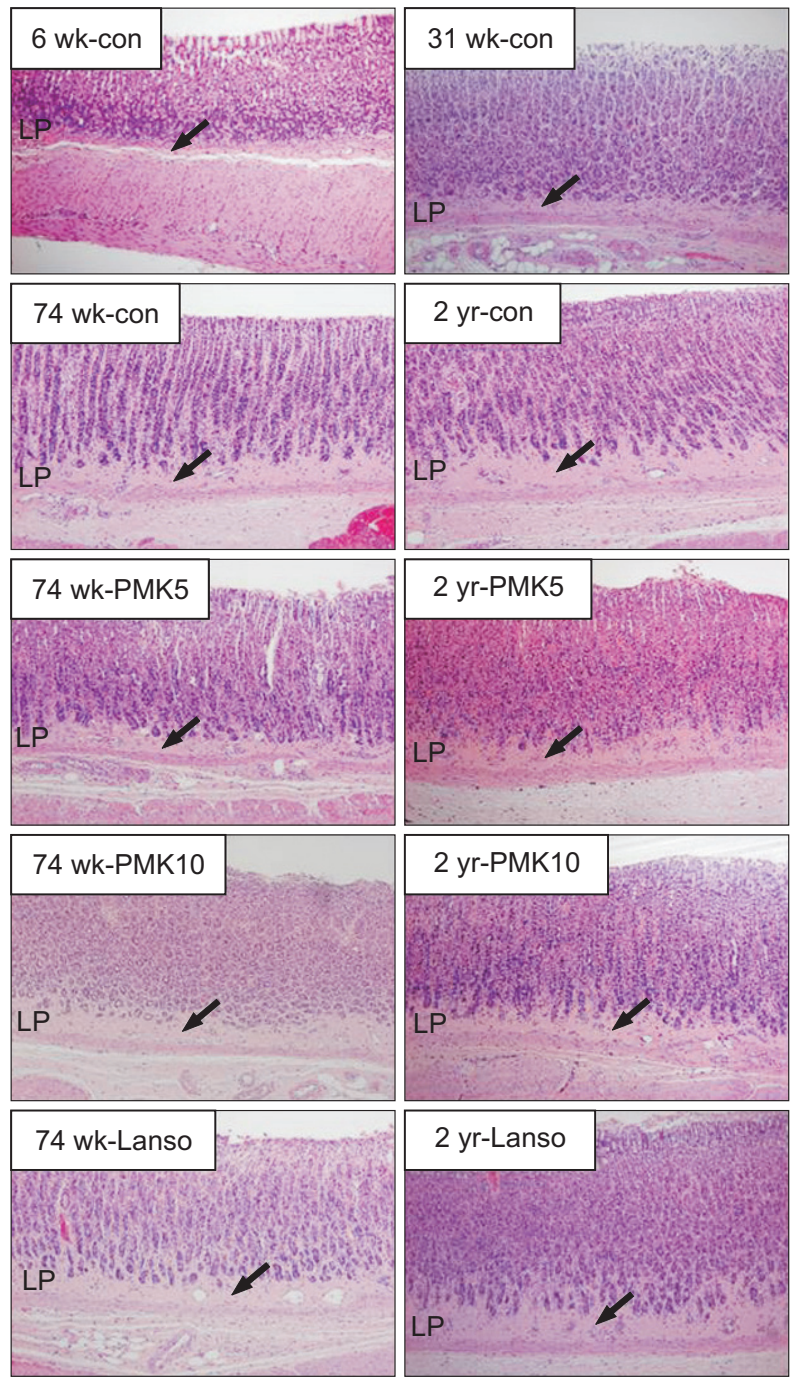

to control group but this discrepancy was statistically significant only in PMK5 group of 2-year-old rats. In the lansoprazole group of 74-week and 2-year-old rats, the connective tissue of lamina propria was similar to that of control group.

\section{Effect of PMK-S005 on age-related change of proinflam- matory cytokines and COX-2 expression}

Since old age itself is already in a state of exaggerated inflammatory condition ${ }^{22}$ we expected that the proinflammatory mediators such as tumor necrosis factor $\alpha(\mathrm{TNF}-\alpha)$, interleukin (IL)-1 $1 \beta$, and COX-2 in the old stomach might be increased. As shown in Fig. 3A and 3B, the production levels of TNF- $\alpha$ and IL- $1 \beta$ in the gastric mucosa were significantly increased with aging. In 74-week and 2-year-old rats, TNF- $\alpha$ and IL-1 $1 \beta$ levels in PMK5 and PMK10 groups were lower compared to those of control group. Especially, age-related increase of TNF- $\alpha$ and IL- $1 \beta$ levels were significantly attenuated in PMK10 group compared to control group $(\mathrm{p}=0.005$ and $\mathrm{p}=0.001$ in 74 -week-

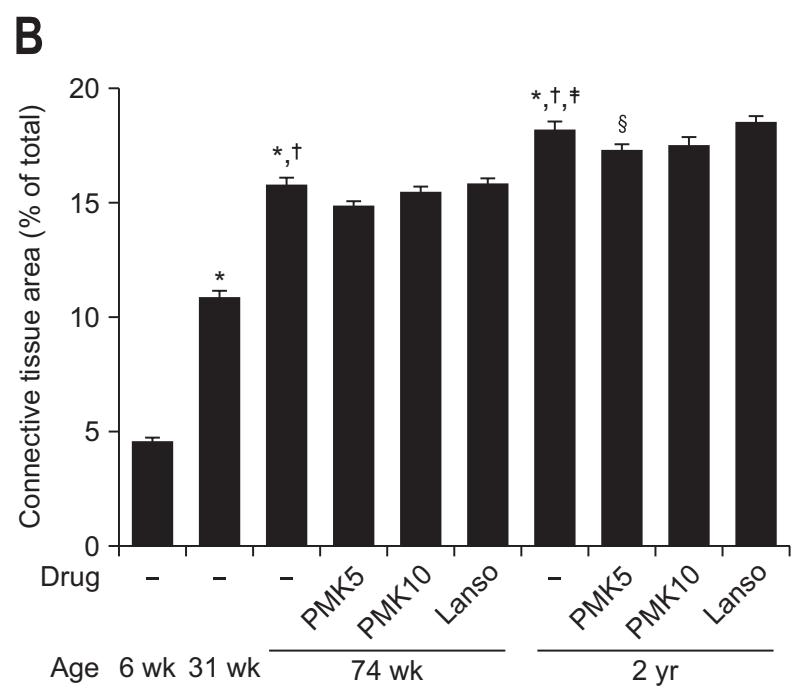

Fig. 2. Connective tissue area in the laminar propria. (A) Histological changes in the gastric mucosa demonstrated by hematoxylin and eosin staining (magnification, $\times 200$ ). The arrows indicate the thickness of the connective tissue. (B) The connective tissue area was measured using a computerized video analysis system (Image-Pro Plus 7.0; Media Cybernetic). The results are expressed as the means \pm SEM of seven animals per group.

PMK5, $5 \mathrm{mg} / \mathrm{kg}$ of PMK-S005; PMK10, $10 \mathrm{mg} / \mathrm{kg}$ of PMK-S005; Lanso, $5 \mathrm{mg} / \mathrm{kg}$ of Lansoprazole; LP, lamina propria. ${ }^{*} \mathrm{p}<0.05$ compared with the 6-week-old controls; ${ }^{\dagger} \mathrm{p}<0.05$ compared with the 31 -weekold controls; ${ }^{+} \mathrm{p}<0.05$ compared with the 74 -week-old controls; ${ }_{\mathrm{p}}^{\mathrm{s}}<0.05$ compared with the 2 -year controls.

old rat, respectively; $\mathrm{p}=0.011$ and $\mathrm{p}=0.007$ in 2-year-old rat, respectively) (Fig. 3A and B). In addition, the inhibitory effects of TNF- $\alpha$ and IL- $1 \beta$ levels were maximized in PMK10 group which was more effective than PMK5 and lansoprazole groups as well. The protein expression of COX-2 was also increased with age and this increase was significantly suppressed in rats fed with PMK-S005 until 74-week and 2-year-old (74 weeks, $p=0.047 ; 2$ years, $p=0.048$ ) (Fig. $3 \mathrm{C}$ and $\mathrm{D}$ ). In the lansoprazole group, the TNF- $\alpha$ and IL- $1 \beta$ levels were lower than those of control group of 74-week and 2-year-old rats (Fig. 3A and B).

\section{Effect of PMK-S005 on age-related change of antioxi- dant enzyme expressions}

One hallmark of the aging process is oxidative stress due to increased prooxidant production and decreased antioxidative capacity. To determine whether the continuous administration of PMK-S005 could affect in oxidative stress status in gastric mucosa, we examined the protein level of antioxidant enzymes 
A

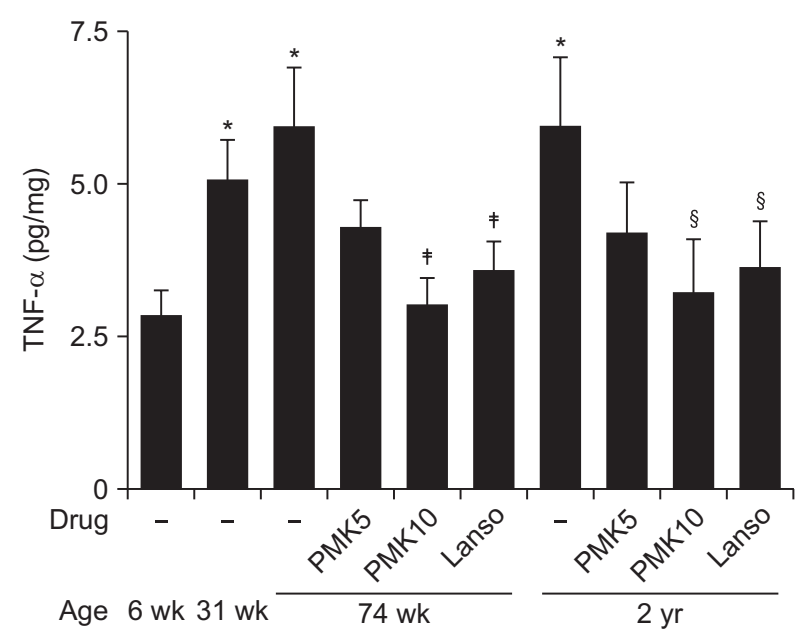

C

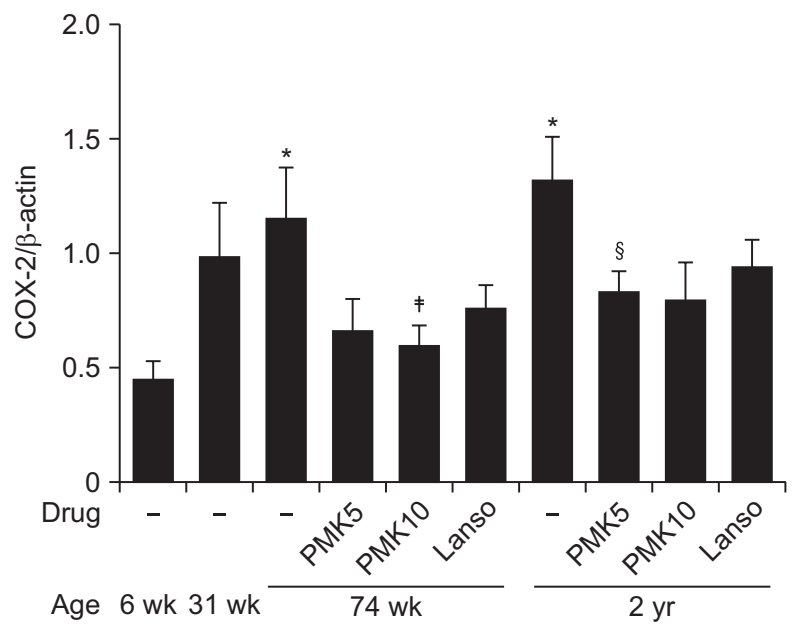

B

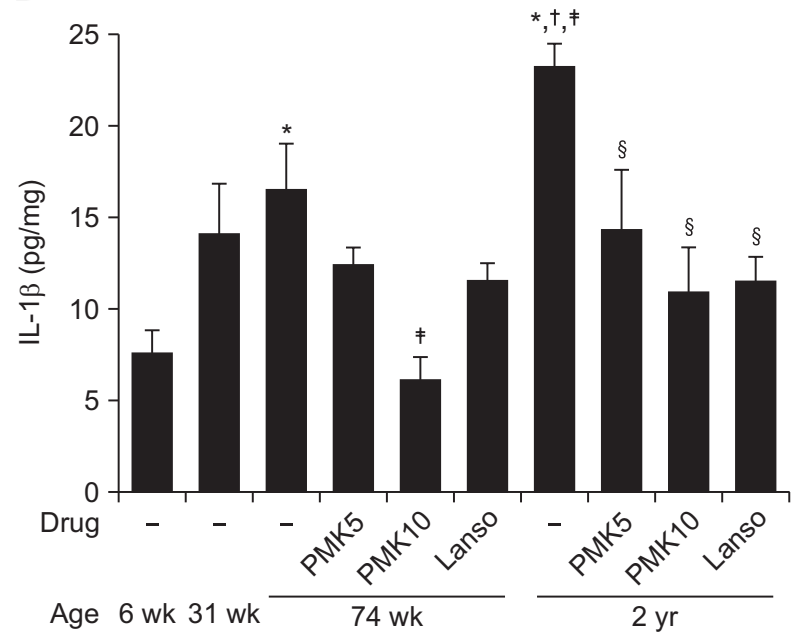

D

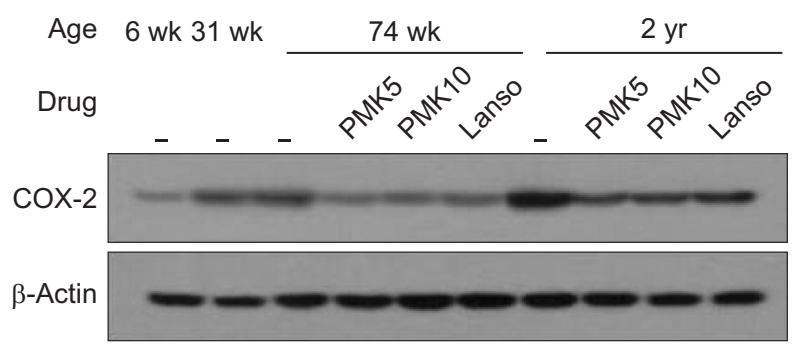

Fig. 3. Effect of PMK-SOO5 on the levels of proinflammatory cytokines and COX-2 expression with aging. The mucosal levels of tumor necrosis factor $\alpha(\mathrm{TNF}-\alpha)(\mathrm{A})$ and interleukin $1 \beta(\mathrm{IL}-1 \beta)(\mathrm{B})$ were determined using an enzyme-linked immunosorbent assay. COX-2 protein expression in the gastric mucosa was evaluated by Western blot analysis (C). A representative Western blot assay is shown (D). The results are expressed as the means \pm SEM of five animals per group.

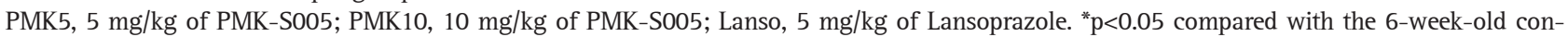
trols; ${ }^{\dagger} \mathrm{p}<0.05$ compared with the 31 -week-old controls; ${ }^{7} \mathrm{p}<0.05$ compared with the 74 -week-old controls; ${ }^{8} \mathrm{p}<0.05$ compared with the 2 -year-old controls.

such as HO-1 and NQO-1 by Western blot. As shown in Fig. 4, the expression of HO-1 and NQO-1 protein showed a pattern of decrease with age. HO-1 protein was significantly decreased in 2-year-old rats compared to 6-week-old rats $(\mathrm{p}=0.008)$. In 74-week old rats, the expression of $\mathrm{HO}-1$ protein in PMK5 and PMK10 groups were higher than that of control group, and PMK5 group showed significant difference $(\mathrm{p}=0.016)$ (Fig. $4 \mathrm{~A}$ and C). NQO-1 protein was also significantly decreased in 2-year-old rats compared to 6-week-old rats $(\mathrm{p}=0.016)$ (Fig. 4B and D). In 74-week old rats, the expression of NQO-1 protein in PMK5 and PMK10 groups were higher than that of control group, and PMK5 group showed significant difference $(\mathrm{p}=0.049)$ (Fig. 4B and D). However, the expression level of HO-1 and
NQO-1 was similar in all experimental groups in 2-year-old rat.

\section{DISCUSSION}

Previous studies have demonstrated that aging is associated with several important abnormalities, including marked changes in the structural and functional properties of the gastrointestinal tract. ${ }^{23,24}$ For example, aging has been shown to cause glandular atrophy which means the replacement of normal glands with connective tissue and decrease the gastric acid secretion. ${ }^{25-28}$

We previously reported that Cochinchina momordica seed extract (SK-MS10) attenuated connective tissue change with age and kept the capacity of acid secretion to that of young 
A

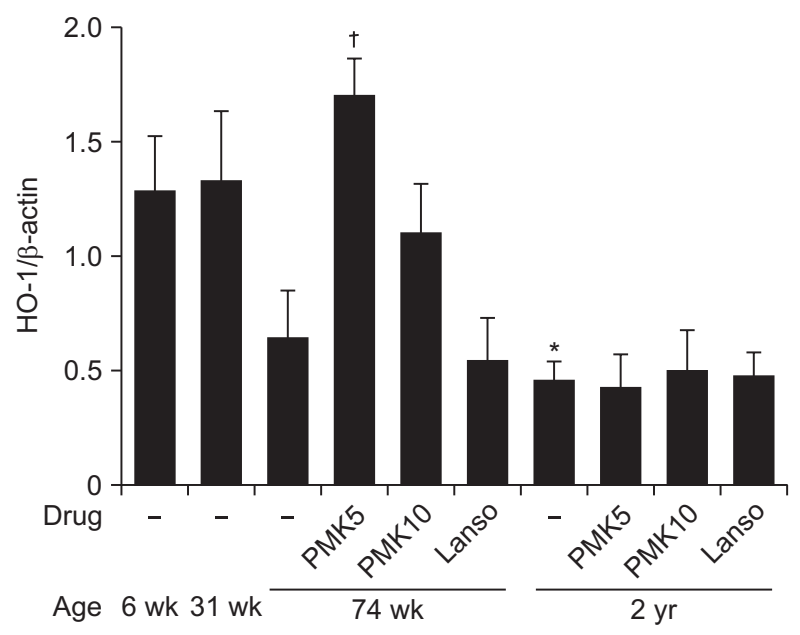

C

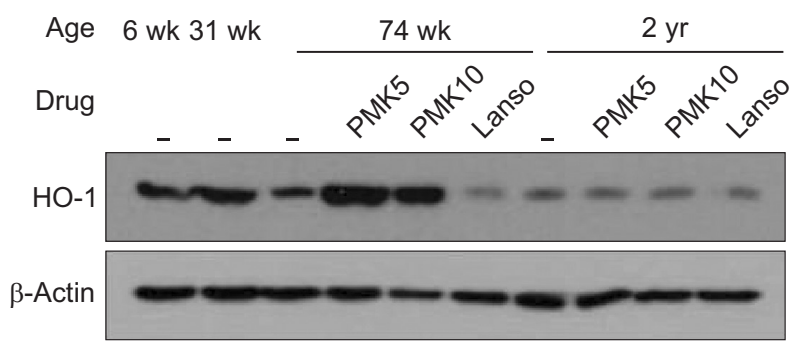

B

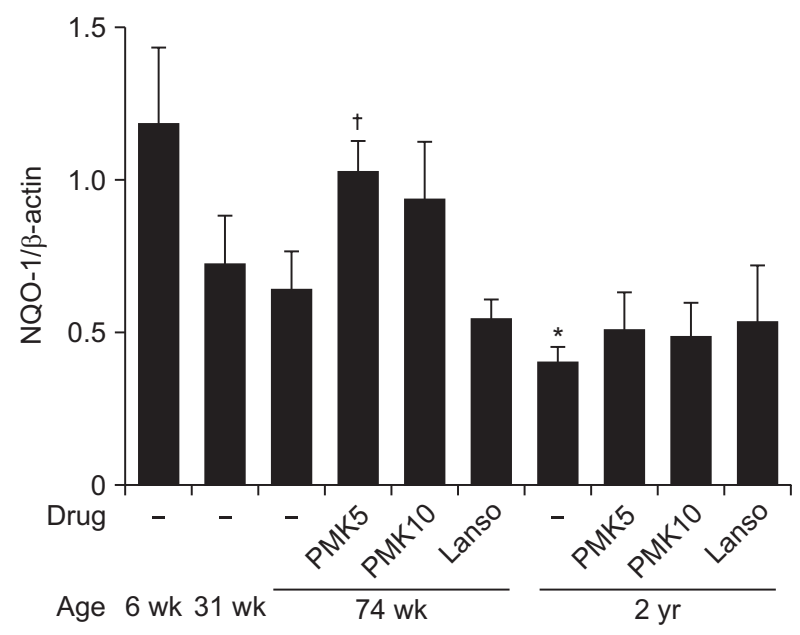

D

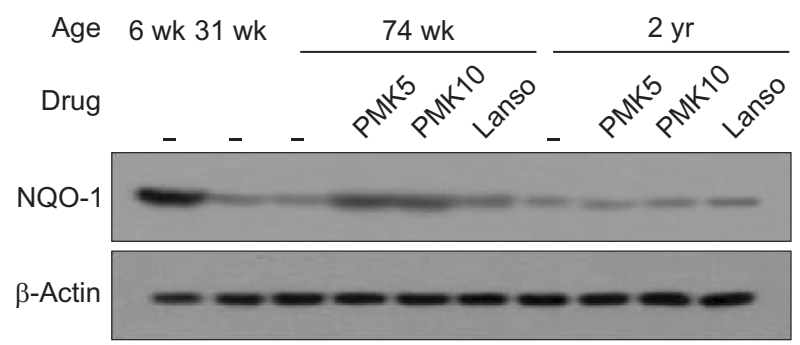

Fig. 4. PMK-S005 relieves the age-related decrease in antioxidant enzymes. Western blot analysis of heme oxyganase 1 (HO-1) (A) and NAD(P) H:quinone oxidoreductase 1 (NQO-1) (B) levels in the rat gastric mucosa. A representative Western blot is shown (C, D). The results are expressed as the means \pm SEM of five animals per group.

PMK5, $5 \mathrm{mg} / \mathrm{kg}$ of PMK-S005; PMK10, $10 \mathrm{mg} / \mathrm{kg}$ of PMK-S005; Lanso, $5 \mathrm{mg} / \mathrm{kg}$ of Lansoprazole. " $\mathrm{p}<0.05$ compared with the 6-week-old controls; ${ }^{\dagger} \mathrm{p}<0.05$ compared with the 74 -week-old controls.

age, suggesting that SK-MS10 might be an antiaging agent in the stomach as well as mucoprotective agent. ${ }^{29}$ In the present study, we found that continuous administration with PMK-S005 reverse the decrease of age-related gastric acid concentration in 74-week-old rats and PMK5 group was more potent than PMK10 group. However, these effects did not more influential in the 2-year-old rats which are comparable to our previous SKMS10 data. ${ }^{29}$ In addition, age-related increment of connective tissue in lamina propria seems to be attenuated in PMK5 group in 74-week and 2-year-old rats but the effect was not that apparent (Fig. 2). We speculate that several factors are changed with increasing age which involved in gastrointestinal function and morphological changes, therefore continuous administration with PMK-S005 may have limitation to overcome the agerelated degeneration of the gastric function.

In contrast to PMK-S005, continuous administration of lansoprazole ( $5 \mathrm{mg} / \mathrm{kg}$ ) inhibited the acid output of stimulated condition (Fig. 1) but there was no significant change in connective tissue thickening (Fig. 2). These results suggest that gastric acid suppression is not a decisive factor against age-related changes. Although, proton pump inhibitors (PPI) are frequently prescribed for treatment of peptic ulcer, long term use of PPI causes small intestinal bacterial overgrowth which could have subsequent effects on the human health. ${ }^{30,31}$ We found that long-term use of lansoprazole (5 mg/kg) causes changes in gut microbiota in the terminal ileum and weight loss (unpublished data).

Alteration of gastric defense mechanism with age may increase the risk of peptic ulcer disease, especially in people who take aspirin and other NSAIDs. ${ }^{8,32-34}$ NSAIDs are widely used in clinical medicine to alleviate the pain and swelling of rheumatoid arthritis and other inflammatory disorder. However, despite their benefit, the use of NSAIDs may cause gastrointestinal bleeding and perforation. ${ }^{9,10}$ Therefore, preventing or delaying the pathogenesis of gastrointestinal diseases is an essential strategy to promote healthy aging, especially more regarding NSAIDs-induced gastropathy.

Recent studies demonstrated that chronic inflammation as a major risk factor underlying aging and age-related diseases. ${ }^{22,35}$ Age-related upregulation of proinflammatory cytokines such as IL-1 $\beta$, IL-6, TNF- $\alpha$, and COX-2 as well as NF- $\kappa$ B activation had been known as important factors involved in the agingassociated inflammatory process. ${ }^{36-38}$ In the current study, we 
found that the expression levels of IL- $1 \beta$, TNF- $\alpha$ and COX-2 in the gastric mucosa were increased with age and these agerelated inductions were inhibited by 5 and $10 \mathrm{mg} / \mathrm{kg}$ of PMKS005 in 74-week and 2-year-old rats. This finding suggests that old stomach was already susceptible condition to inflammation, which conditions were ameliorated by continuous administration of PMK-S005.

Several reports indicated that the age-related structural and functional alterations are mostly a consequence of increased oxidant generation and reduced antioxidant capacity. ${ }^{39}$ Besides, aging leads to increased lipid peroxidation and ROS generation in gastric mucosa, too. ${ }^{15}$ An imbalance between the formation and elimination of ROS and the production of oxidative stress plays a vital role in aging and age-associated diseases. Therefore, recent studies have focused on the use of natural antioxidants to protect the gastrointestinal mucosa of patients who take NSAIDs. Vegetables and fruits are important dietary sources of natural antioxidants and have been shown to act as effective ROS scavengers, metal iron chelators and trapping agents for reactive carbonyl species, and they may play an important role in gastrointestinal protection. ${ }^{40}$ Therefore, naturally occurring antioxidants may be useful for the prevention of and/ or therapeutic intervention against gastrointestinal disorders caused by oxidative damage. One of the well-known sources of phytochemicals that have been studied is garlic and its derivative. SAC, the most abundant sulfur-containing amino acid derived from garlic, has been reported to have multiple biological properties such as antioxidant, ${ }^{16}$ anti-inflammatory, ${ }^{17}$ anticancer, ${ }^{18}$ and antihepatotoxic activities. ${ }^{41}$

In the present study, we showed that antioxidant enzymes including HO-1 and NQO-1 are decreased with age. However, continuous administration with $5 \mathrm{mg} / \mathrm{kg}$ of PMK-S005 in 74-week-old rats sustained the level of HO-1 and NQO-1 to that of 6-week-old rats (Fig. 4). These results suggest that PMKS005 could reverse the impairment of the antioxidant enzymes in the gastric mucosa induced with aging. Recently, we found that 2-week administration of PMK-S005 (5 and $10 \mathrm{mg} / \mathrm{kg}$ ) induced antioxidant enzyme including HO-1, NQO-1, GCLC and GCLM which may responsible for gastroprotective effects of PMK-S005. ${ }^{21}$ Previous research suggested that up-regulation of antioxidant enzymes may be the most critical cytoprotection mechanism against oxidative stress. Kirkby and Adin ${ }^{42}$ suggested that HO-1 breaks down heme to biliverdin and carbon monoxide, which play an important role to protect gastrointestinal cell against oxidative damage. In addition, Guo et al. ${ }^{43}$ reported that the increased expression of HO-1 may inhibit inflammation and tissue damage caused by ROS in the GI tract. Consequently, we speculated that antiaging effect of PMK-S005 may be due to partly to its beneficial action on defensive mechanism such as antioxidants and partly to its inhibitory effect on inflammatory factors that increase with age. However, further studies are needed to elucidate precise mechanism underlying our results.
Although the effects of PMK-S005 were not dose dependent manner and somehow less effective in PMK10 group compared to the PMK5 group, these results suggest that less than $10 \mathrm{mg} /$ $\mathrm{kg}$ of PMK-S005 could exert significantly its antiaging effect. In conclusion, continuous administration of PMK-S005 sustained the capacity of gastric acid secretion to that of young age, attenuated connective tissue change with age, inhibited the increment of inflammatory mediators with age, and reversed the age-related impairment of antioxidant enzyme. These findings suggest that PMK-S005 ameliorated the age-related inflammation and antioxidant enzyme which may offer a potential therapeutic approach for age-related gastric disorders. Further study might be promising to perform the underlying molecular mechanisms of PMK-S005 in the aspect of antiaging agent in the stomach.

\section{CONFLICTS OF INTEREST}

No potential conflict of interest relevant to this article was reported.

\section{ACKNOWLEDGEMENTS}

This work was supported by grant number 08-2014-069 from the Seoul National University Bundang Hospital Research and by Chungcheong leading industry promotion project of the Korean Ministry of Knowledge Economy.

\section{REFERENCES}

1. Grassi M, Petraccia L, Mennuni G, et al. Changes, functional disorders, and diseases in the gastrointestinal tract of elderly. Nutr Hosp 2011;26:659-668.

2. Feldman M, Cryer B, McArthur KE, Huet BA, Lee E. Effects of aging and gastritis on gastric acid and pepsin secretion in humans: a prospective study. Gastroenterology 1996;110:1043-1052.

3. Somerville K, Faulkner G, Langman M. Non-steroidal anti-inflammatory drugs and bleeding peptic ulcer. Lancet 1986;1:462-464.

4. Pilotto A. Aging and the gastrointestinal tract. Ital J Gastroenterol Hepatol 1999;31:137-153.

5. Lee M, Hardman WE, Cameron I. Age-related changes in gastric mucosal repair and proliferative activities in rats exposed acutely to aspirin. Gerontology 1998;44:198-203.

6. Lee M, Feldman M. Age-related reductions in gastric mucosal prostaglandin levels increase susceptibility to aspirin-induced injury in rats. Gastroenterology 1994;107:1746-1750.

7. Miyake H, Inaba N, Kato S, Takeuchi K. Increased susceptibility of rat gastric mucosa to ulcerogenic stimulation with aging: role of capsaicin-sensitive sensory neurons. Dig Dis Sci 1996b;41:339345.

8. Lee M, Feldman M. The aging stomach: implications for NSAID gastropathy. Gut 1997;41:425-426. 
9. Sostres C, Gargallo CJ, Arroyo MT, Lanas A. Adverse effects of non-steroidal anti-inflammatory drugs (NSAIDs, aspirin and coxibs) on upper gastrointestinal tract. Best Pract Res Clin Gastroenterol 2010;24:121-132.

10. Zullo A, Hassan C, Campo SM, Morini S. Bleeding peptic ulcer in the elderly: risk factors and prevention strategies. Drugs Aging 2007;24:815-828.

11. Lenaz G, Bovina C, D'Aurelio M, et al. Role of mitochondria in oxidative stress and aging. Ann N Y Acad Sci 2002;959:199-213.

12. van der Vliet A, Bast A. Role of reactive oxygen species in intestinal diseases. Free Radic Biol Med 1992;12:499-513.

13. Devasagayam TP, Tilak JC, Boloor KK, Sane KS, Ghaskadbi SS, Lele RD. Free radicals and antioxidants in human health: current status and future prospects. J Assoc Physicians India 2004;52:794804.

14. Surh YJ. Cancer chemoprevention with dietary phytochemicals. Nat Rev Cancer 2003;3:768-780.

15. Kang JM, Kim N, Kim JH, et al. Effect of aging on gastric mucosal defense mechanisms: ROS, apoptosis, angiogenesis, and sensory neurons. Am J Physiol Gastrointest Liver Physiol 2010;299: G1147-G1153.

16. Ray B, Chauhan NB, Lahiri DK. Oxidative insults to neurons and synapse are prevented by aged garlic extract and S-allyl-L-cysteine treatment in the neuronal culture and APP-Tg mouse model. J Neurochem 2011;117:388-402.

17. Mong MC, Yin MC. Nuclear factor kappaB-dependent anti-inflammatory effects of s-allyl cysteine and s-propyl cysteine in kidney of diabetic mice. J Agric Food Chem 2012;60:3158-3165.

18. Thomson M, Ali M. Garlic [Allium sativum]: a review of its potential use as an anti-cancer agent. Curr Cancer Drug Targets 2003;3: 67-81.

19. Moriguchi T, Saito H, Nishiyama N. Anti-ageing effect of aged garlic extract in the inbred brain atrophy mouse model. Clin Exp Pharmacol Physiol 1997;24:235-242.

20. Choi YJ, Kim N, Lee JY, et al. Protective effects of garlic extract, PMK-S005, against nonsteroidal anti-inflammatory drugs-induced acute gastric damage in rats. Dig Dis Sci 2014;59:2927-2934.

21. Choi YJ, Kim N, Lee JY, et al. Gastroprotective effects of PMKS005 against ethanol-induced acute gastric damage in rats. Gut Liver 2016;10:348-355.

22. Chung HY, Lee EK, Choi YJ, et al. Molecular inflammation as an underlying mechanism of the aging process and age-related diseases. J Dent Res 2011;90:830-840.

23. Geokas MC, Conteas CN, Majumdar AP. The aging gastrointestinal tract, liver, and pancreas. Clin Geriatr Med 1985;1:177-205.

24. James OF. Gastrointestinal and liver function of old age. Clin Gastroenterol 1983;12:671-691.

25. Hollander D, Tarnawski A, Stachura J, Gergely H. Morphologic changes in gastric mucosa of aging rats. Dig Dis Sci 1989;34:1692-1700.

26. Majumdar AP, Jasti S, Hatfield JS, Tureaud J, Fligiel SE. Morpho- logical and biochemical changes in gastric mucosa of aging rats. Dig Dis Sci 1990;35:1364-1370.

27. Khalil T, Singh P, Fujimura M, et al. Effect of aging on gastric acid secretion, serum gastrin, and antral gastrin content in rats. Dig Dis Sci 1988;33:1544-1548.

28. Maitra RS, Edgerton EA, Majumdar AP. Gastric secretion during aging in pyloric-ligated rats and effects of pentagastrin. Exp Gerontol 1988;23:463-472.

29. Jo HJ, Kim N, Nam RH, et al. The effect of Cochinchina momordica seed extract on gastric acid secretion and morphologic change in aged rat stomach. Gut Liver 2013;7:560-568.

30. Pham CQ, Regal RE, Bostwick TR, Knauf KS. Acid suppressive therapy use on an inpatient internal medicine service. Ann Pharmacother 2006;40:1261-1266.

31. Lo WK, Chan WW. Proton pump inhibitor use and the risk of small intestinal bacterial overgrowth: a meta-analysis. Clin Gastroenterol Hepatol 2013;11:483-490.

32. Kim SW, Parekh D, Townsend CM Jr, Thompson JC. Effects of aging on duodenal bicarbonate secretion. Ann Surg 1990;212:332337.

33. Hinsull SM. Effect of colloidal bismuth subcitrate on age related gastric lesions in the rat. Gut 1991;32:355-360.

34. Grønbech JE, Lacy ER. Role of gastric blood flow in impaired defense and repair of aged rat stomachs. Am J Physiol 1995;269(5 Pt 1):G737-G744.

35. Wu D, Ren Z, Pae M, et al. Aging up-regulates expression of inflammatory mediators in mouse adipose tissue. J Immunol 2007;179:4829-4839.

36. Jung KJ, Lee EK, Yu BP, Chung HY. Significance of protein tyrosine kinase/protein tyrosine phosphatase balance in the regulation of NF-kappaB signaling in the inflammatory process and aging. Free Radic Biol Med 2009;47:983-991.

37. Chung HY, Kim HJ, Kim KW, Choi JS, Yu BP. Molecular inflammation hypothesis of aging based on the anti-aging mechanism of calorie restriction. Microsc Res Tech 2002;59:264-272.

38. Kim HJ, Kim KW, Yu BP, Chung HY. The effect of age on cyclooxygenase-2 gene expression: NF-kappaB activation and IkappaBalpha degradation. Free Radic Biol Med 2000;28:683-692.

39. Schmucker DL. Age-related changes in liver structure and function: implications for disease? Exp Gerontol 2005;40:650-659.

40. Halliwell B, Zhao K, Whiteman M. The gastrointestinal tract: a major site of antioxidant action? Free Radic Res 2000;33:819-830.

41. Kodai S, Takemura S, Minamiyama Y, et al. S-allyl cysteine prevents $\mathrm{CCl}(4)$-induced acute liver injury in rats. Free Radic Res 2007;41:489-497.

42. Kirkby KA, Adin CA. Products of heme oxygenase and their potential therapeutic applications. Am J Physiol Renal Physiol 2006;290:F563-F571.

43. Guo X, Shin VY, Cho CH. Modulation of heme oxygenase in tissue injury and its implication in protection against gastrointestinal diseases. Life Sci 2001;69:3113-3119. 